\title{
THE EFFECT OF HUMAN RELATION IN SOLVING CONFLICTS IN AN ORGANIZATION
}

\author{
Dr. C K GOMATHY, Ms. B.LALITHA, Ms.CH.L.SOWJANYA, Ms. CH.JAHNAVI \\ Sri Chandrasekharendra Saraswathi Viswa Mahavidyalaya , Kanchipuram
}

\section{ABSTRACT}

Conflicts in organisations do when interests and conditioning of individualities or groups within an association defy each other and help attainment of one party "s objects. When conflicts aren't well managed, workers come displeased and tend to bear in a way that doesn't promote good connections among workers for the attainment of organisational pretensions. By means of furnishing empirical defense for these assertions, the study sought to establish the connections that live among conflict operation, communication and connections at work. Employing thecross-sectional check approach, 132 workers were tried from two major manufacturing companies in Ghana videlicet, Interplast Company Limited and Duraplast Company Limited. The study variables ( Conflict operation, communication and connections at work) were measured using scales from the fourteen confines of the Organisational Climate Questionnaire (OCQ) developed by Furnham and Godstein(2007). The Karl Pearson "s Product moment correlation analysis was used to establish the connections among the study variables whereas the hierarchical retrogression analysis was used to find the causal and moderating goods of the independent variables on the dependent variable. The results verified that there live a significant positive relationship between conflict operation and communication at the plant $(\mathrm{r}=.469, \mathrm{p}<.01)$. The findings of the study supported the assertion that there's a significant positive relationship between communication and connections at work $(r=.369$, $\mathrm{p}<.01)$. The study also revealed that there's significant positive relationship between conflict operation and connections at work $(\mathrm{r}=.582, \mathrm{p}<.01)$. Eventually, the findings supports the assertion that communication will moderate the relationship between conflict operation and connections at work. Operation within the manufacturing companies must admit the fact that when conflict are duly managed using applicable communication channels, there's always trust between them and workers which further helps to save time on misreading and ameliorate upon connections at work. The findings of this study will give guidelines for policy, stylish practice and strategies for managing conflicts and perfecting connections among workers. Also, the findings will give feedback which will be necessary for enhancement and development of workers in the manufacturing and other sectors of the frugality.

\section{Keywords:}

conflicts, conflict operation, communication, connections at work, manufacturing sector.

\section{I . INTRODUCTION}

Appreciation of conflict operation among workers at plant is one of the essential though neglected areas within associations. Lazarus is of the view that, despite thousands of times of work by scholars on the part of conflict among co-workers in associations, the scientific study of conflict within academia is a fairly recent miracle. Conflict is regarded as the presence of disharmony that occurs when the Pretensions, interests or values of different 
individualities or groups are inharmonious and frustrate each other ${ }^{\text {e }} \mathrm{s}$ trying to achieve objects. Thus conflict is necessary part of organizational life since the purpose of different stakeholders analogous as directors and staffs are constantly unharmonious.

\section{CONFLICT MANAGEMENT IN ORGANISATIONS}

Conflict is a form of social commerce and social situation, where interest and conditioning of individualities or groups within an association generally defy each other and help attainment of one party "s objects. According to Nutt, conflict is expressed in terms of dissensions among stakeholders about situations of threat, unborn conditions, core problems, indispensable ways of dealing with problems and criteria for assessing these druthers. Choudrie is of the view that when people from different backgrounds and gests work together, conflicts are bound to arise. He plant that conflicts aren't productive for associations and thus conflict resolution is sought to insure peace and understanding. Chourdrie states that, there are two forms of conflict that live within work psychology literature and these are affective and substantial conflict. Therefore relationship between individualities and is of particular in nature. The third conflict editorialized by these authors is the inter-group conflict. This form of conflict arises between groups, platoon or department. The fourth type of conflict is known as inter-organizational conflict and occurs across associations.

In the history, operation philosopher used the term conflict avoidance. Still, moment the expression is decreasingly replaced by conflict operation. In recent times effective directors use conflict effectively for particular development, to address organizational problems, to increase critical alert and tone- appraisal and farther examine conflict values when making opinions. Conflict operation fete that indeed though conflict come On with its own negative counteraccusations, it also bring about great benefits. As a result, directors in the twenty first century don't seek to avoid conflict rather manage conflict in the association. Conflict is Aggravated moment by changes in technology, global shifting of power, political uneasiness and fiscal uncertain. To some directors this ineluctable discord is lamentable and should be avoided at cost. To others conflict represents instigative responsibility for the future of every association (Robinson, 1987).

\section{III.THE ROLE OF COMMUNICATION IN CONFLICT MANAGEMENT}

Some inquiries have reported on the significant part that communication plays in conflict and conflict operation (Putnam 2006; Aula \& Siira 2007). Atkinson and Butcher(2003) hypothecate that, communication is essential to erecting trust within an association performing in reduced conflicts and increased positive organizational climate( Aubert \& Kelsey, 2003). As indicated by Nordin, Sivapalan, Bhattacharyya, Hashim, Ahmad, Abdullah, (2014) in their quantitative exploration in gas and canvas company, the results of the study revealed that good communication climate associate Appreciatively to conflict operation and conclude that the significance of organizational communication still can not be overlooked in conflict resolution.

Still for this study our focus will be on direction of communication. This involves perpendicular communication (overhead and over 
communication), vertical and slant communication. According to TariszkaSemegine(2011) perpendicular communication is concerned with communication between workers at different hierarchical situations in the association. It focuses on downcast and upward communication between directors and workers. Vertical communication is concerned with communication between workers at the same position in the association. It focuses on communication between peers, people, at equal or veritably nearly equal situations in the association. Cheney (2011) explains downcast communication as the type of communication that flows from upper operation down to the workers at lower species. Lunenburg(2010) is of the view that downcast communication generally is effective when upper situations of operation are largely motivated to make it work.

Upward Communication is the inflow of information from inferiors to elders in an association that move from a lower position to a advanced position (Richmond, McCroskey, \& McCroskey, 2005). Information from Inferiors to their elders through upward scale typically consists of ideas, suggestions, reports, complaints and examens. Although upward communication is initiated by those at the lower situations of the association, it can be successful only if those at the advanced situations are willing to allow the communication to be effective.

Vertical Communication is communication that flows across the association (from peer to peer to peer). Vertical communication frequently focuses on hand satisfaction and hand morale. This form of communication generally encourage equivalence involve to can talk and partake openly and freely about their passions, the system and bandy problems with others who can identify with them. In addition, this is also the channel at which utmost social commerce takes place within the formal association. It's through the vertical channels that individualities are likely to increase their knowledge, communication chops and socialization chops. This further helps to establish long- lasting interpersonal Connections that can help you in getting a better hand with a better chance of survival in the association (Sostek, 2006).

Slant communication refers to communication between directors and workers located in different functional divisions (Wilson, 1992). Therefore information inflow isn't affected by hierarchical position. Thus communication can flow at colorful situations transversely. Someone who's a elderly in one department may deal directly with a inferior in another department. This type of communication relies heavily on cooperation among members involved( Cheney 2011).

\section{IV . RELATIONSHIPS AT WORK}

Work is abecedarian to the mortal condition and determines what we do for important of our waking lives and it preoccupies much of what we suppose about(Abbott, 2006). Thus good connections at work are vital to the plant, whether at the time of reclamation, during an workers " term or at the time of separation (Leat, 2008).their efforts towards work and providing them with gift vouchers and even giving them bonuses might even make them more trustworthy towards the company.By all these activities an employee can develop morality in himself and works effectively which makes the company's growth.

Employers and workers are all crucial players in this relationship. Achieving and sustaining this ideal 
state doesn't always do due to some misreading that might arise. Therefore workers occasionally might not meet certain prospects, conflict and other factors that challenge group dynamics similar as law and other compliance issues live and directors and administrators don't lead or address a given situation. Consequently, to make healthier relationship at work it's thus necessary to insure that these issues are managed correctly and pertinently.

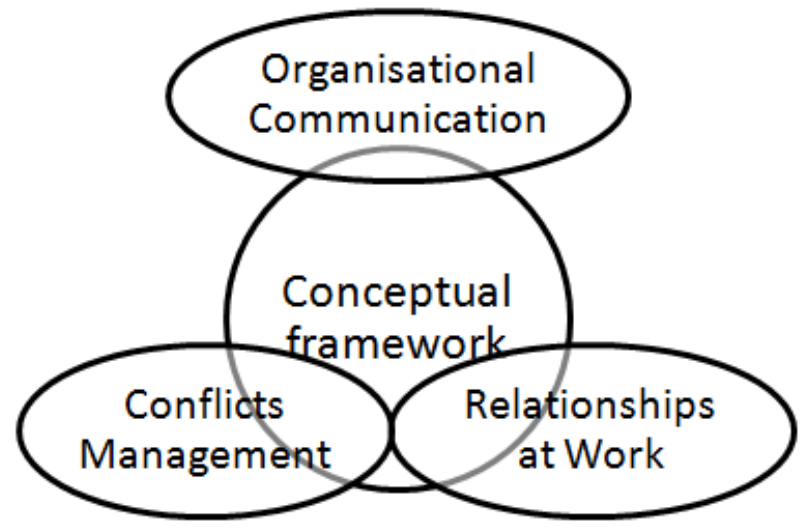

Fig 1: Conflict Management, Communication and Relationships at Work

\section{V..RESULTS}

To give a better interpretation of our commerce results, the standard procedure of conniving the relationship between conflict operation and relationship at work. Mean 1 Standard divagation was used to represent high position communication and Mean-1 standard divagation was used to represent low position communication. Figure 1 shows that there's a significant positive relationship between conflict operation and relationship at work and this relationship is moderated by communication.

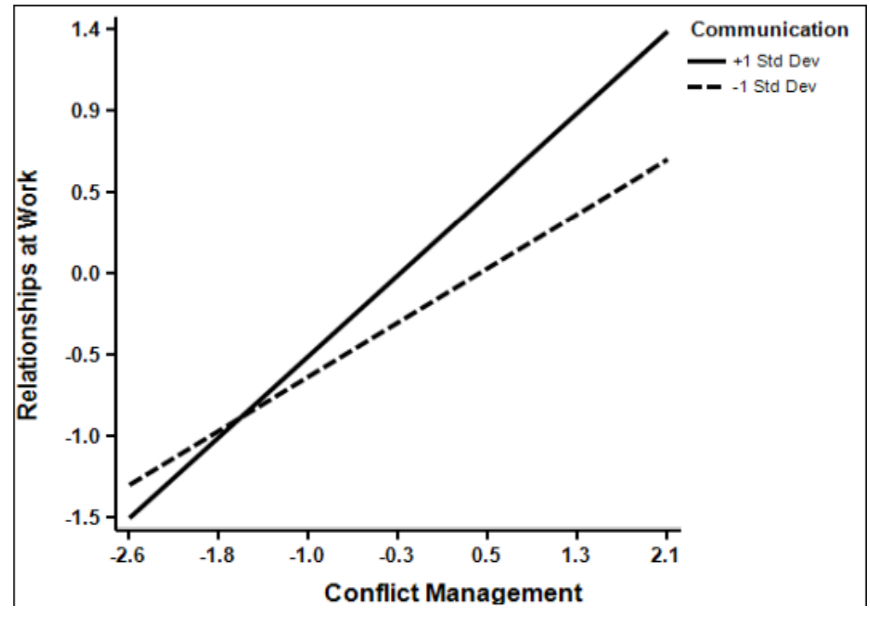

Fig 2: Moderating Effect of Communication on the Relationship between Conflict Management and Relationships at Work.

\section{LIMITATION OF THE STUDY}

As with all empirical exploration, this study isn't without limitations as it didn't fully cover every aspect that has ever been bandied about conflict operation, communication and connections at work. The findings of this study handed some unique perceptivity into the way conflicts are managed in organisations and the softening effect that communication has in promoting good connections at work. Still, the small sample size limited the generalizability of the study. Secondly, the exploration was confined to the plastic manufacturing sector which offers a exploration gap for other studies to probe into.

Another limitation is the cross-sectional check design employed to measure the impact of conflict operation on hand connections at work within a period of time. The situation revealed in the study may be different on another occasion. Thus, unborn studies could turn this exploration into a nonstop shadowing (longitudinal) study to more understand 
the changes in how conflict operation influences connections among workers over time.

\section{VII.CONCLUSION}

By observing all these above scopes and using various methods with certain limitations we can say that conflicts are very common problem in every organisation between employees and they can be solved by humans as said above like they can be solved by their friends, colleagues, high officials or managers in a cool way. So by this we can conclude that by raising conflicts work effects in an organization. So by using human force we can solve them.

\section{VIII.REFERENCES}

1. Abbott, K. (2006). A Review of Employment Relations Theories. Problems and Perspectives in Management, 1, 187 -199

2. Adejimola, A. S. (2009). Language and communication in conflict resolution: Journal of Law and Conflict Resolution, 1(1), 001-009

3. Adomi, E.E. \& S.O. Anie, (2005). Conflict management in Nigerian University libraries. J. Library Manage, 27, 520-530

4. Ali D. Akkirman \& Drew L. Harris, (2005),"Organizational communication satisfaction in the virtual workplace", Journal of Management Development, 24(5)397 - 409

5.Dr.C K Gomathy, Article: A Study on the recent Advancements in Online Surveying, International Journal of Emerging technologies and Innovative
Research ( JETIR ) Volume 5 | Issue 11 | ISSN : 2349-5162, P.No:327-331, Nov-2018

6.Dr.C.K.Gomathy,C K Hemalatha, Article: A

Study On Employee Safety And Health

Management International Research Journal Of

Engineering And Technology (Irjet)- Volume: 08

Issue: 04 | Apr 2021

7. Dr.C K Gomathy, Article: A Study on the Effect of Digital Literacy and information Management, IAETSD Journal For Advanced Research In Applied Sciences, Volume 7 Issue 3, P.No-51-57, ISSN NO: 2279-543X,Mar/2018

\section{AUTHOR'S PROFILE:-}

1.

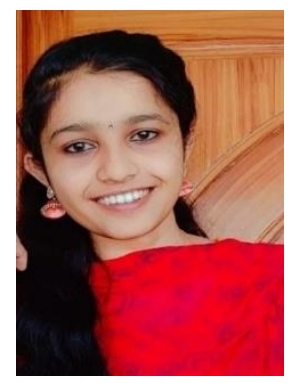

Ms.B.Lalitha, Student ,B.E. Computer Science and Engineering , Sri Chandrasekharendra Saraswathi Viswa Maha Vidhyalaya Enathur, Kanchipuram,India. Her area of interest in Human Resources Development 
2.

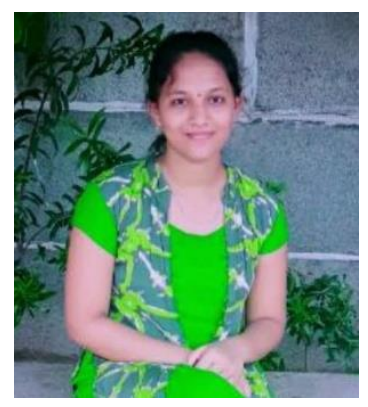

Ms.CH.Jahnavi, Student, B.E. Computer Science and Engineering, Sri ChandraSekhrendra Saraswathi Viswa MahaVidyalaya Enathur ,Kanchipuram, India. His area of interest in Human Resources Development.

3.

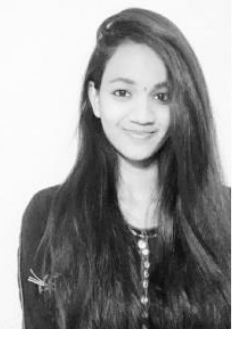

Ms. CH.L.Sowjanya , Student, B.E Computer

Science and Engineering, Sri Chandrasekharendra Saraswathi Viswa MahaVidyalaya,Enathur, Kanchipuram, India. Her area of interest in Human Resources Development.

4.

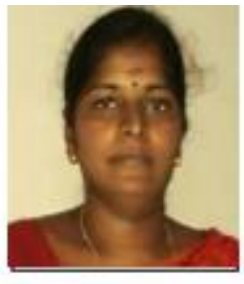

Dr.C.K.Gomathy is Assistant Professor in Computer Science and Engineering at Sri Chandrasekharendra Saraswathi Viswa MahaVidyalaya,Enathur,Kanchipuram,India.Her area of interest in Software Engineering, Web Services, Knowledge Management and IOT. 